\title{
Satisfaction from Internship Program and Changing Attitude: A Perceptual Survey from Hotel Management Students
}

\section{Prakash Kumar Gautam*}

\begin{abstract}
Internship is a profession-oriented learning technique translating the knowledge into professional skills. It helps to equip future human resources with operational skills and enhanced social relationship. Satisfaction through internship program develops different attitudes which may lead loyalty, job commitment, extended efforts, etc. As it provides more independence and opportunity of social networking, it may change the attitude of the person. This piece of research is intended to estimate the level of satisfaction among the hotel management students and explore their attitude towards their decision regarding future profession. Structured questionnaire prepared both in English and Nepali was used to collect the response. Convenient as well as snow ball sampling are used as sampling techniques. Descriptive analytical tools are used to draw the conclusion. This study concludes that majority of the students are satisfied from the intern opportunity and hence they wish to join hotel industry. This study has observed low but positive and significant relationship with satisfaction and intention of changing attitude. This study has also explored the fact that there no gender influence in satisfaction level of the intern students but male students are more prone to change on behavioural intention. Students are positive regarding their career choice but are found of developing negative attitude towards college management as well as in-college activities.
\end{abstract}

Key Words : Internship, behavioural intention, social relationship, snow ball sampling, curriculum development.

* Mr. Gautam, Lecturer of Shankerdev Campus, Tribhuvan University. He can be reached at pkg@shankerdevcampus.edu.np; gdpconsultingnepal@gmail.com 


\section{General Background}

There is disagreement between academicians and business world regarding the quality of students in higher education. Academic world claims that their products have sufficient skills quality essential to the job they join. In contrast, business world blames that universities produce students with only knowledge which is not enough to handle the changing job responsibilities required to produce competiveness. It is the ground reality that universities should produce human capital that must fit for business world. They should have sufficient skills required for shifting job requirement. For this, knowledge should be transformed into skills. Universities, with this realization, have brought different academic programs with the provision of internship. This helps to make students familiar with real working environment to explore, identify and solve the job related problems.

Internship is profession-oriented learning technique that aims to prepare students with work-related skills and expertise essential to future career (Chen, et al. 2011). Internship helps to familiarize students with practical skills, enhance social relationship, motivate future learning and develop a socially acceptable personality (Calloway \& Beckstead, 1995). Internship prepares students fit for changing demand of business world but on the flipside, if the students experience poor satisfaction, they may change their attitude towards their choice of subject and college. Students may develop both negative as well as positive attitude and behaviour because of intern experience. Positive attitude results in loyalty and willingness to offer more while negative attitude results in regret for their choice in future career, negative word of mouth towards program and the college. Internship programs intend to create experience and behavioural intentions as basic output of the university program which aims to facilitate in acquiring career values and enhancing personal development.

Students learn social and job skills practically at work through internship programme and become more independent and increase their social experience (Chen, et al. 2011). This helps to fulfill the requirement of business world as it concerns with practical skills and expertise. Hotel Management students enroll internship for one year according to university requirement. Such internship programs are offered for Nepalese students in Star Hotels in Nepal, India, Malaysia, China, Thailand, Dubai and Singapore. Internship programs are full time programs in which students are expected to work in different departments or work areas. Many students after internship programs demonstrate unexpectedly changed behaviour. It explores a question whether internship programs 
change the attitude and behavior of students? Wang (2002) reported that many graduates are unable to handle the work-related challenges during their internship period. Interestingly, as West and Jameson (1990) suggested that more students participate in internship program in their college years and experience real work situation, the less likely they want work in that field on completion of their studies. This is because of bad internship experience discouraged from work demands in related field. This study explores to what extent hotel management students in Nepal are satisfied from intern and willing to join the same field as long career.

\section{Review of Literature and Research Objectives}

Haung and Haund (2004) reported that once students are engaged in their career, who have graduated from colleges often realize the difference between real work-situations and theory they learnt. Universities aim to prepare Hotel Management students competent both in the theoretical knowledge and practical skills required for their jobs in hotel industry by imparting managerial knowledge and skills essential to handle managerial jobs. Both business world and universities are working to fulfill the gap between theoretical knowledge provided through class rooms' teaching-learning activities and real work-situation demand. Students are acquiring knowledge and work-related skills both in colleges and hotel industry through effective internship experience.

Internship is a structured learning experience in a work setting that provides a student an opportunity to learn about a career interest and gain valuable knowledge and experience in a particular field (Dortch, 2003). Likewise, Hurst et al. (2012) explained internship as a helpful tool to strengthen student's marketable skills like communication, timemanagement, self-confidence, and self-motivation. Positive experience gained through internship encourages students for joining the same industry of their first choice. Internship program helps to fulfill the gap between job requirements and skill availability in the students. Rok (2013) revealed a significance positive relationship between internships and student's job performance. He reported that respondents expressed satisfaction with experience gained; their remarks prove that this affected positively to their self-confidence and self-motivation.

Recovery knowledge at the end of internship was positively associated with increase in intern's confidence and competence but was not associated with changes in the interns' 
attitudes (Crowe, et al. 2013). Watson, et al. (2006) have mentioned that skills and knowledge of clinical management are required, at the same time, it was also found that staffs' attitudes have direct impact on the extent to which knowledge is accepted and used. Attitudes, knowledge, confidence, and competency are thought to closely associated (Bedregal, O'Connell, \& Davidson, 2006; Siegfried et al., 2007). Various researchers have mentioned that internship programs not only improve the job-related skills but they form attitude towards the future career, present working environment, management, etc.

Many students, in Nepal, select the future career with influence of their parents, teachers, relatives and friends even without analyzing their self interest, future prosperity of career as well as personality-career match. Such trend seems to be significantly high in Hotel Management students. Hotel Management colleges try to shape student's attitude and behaviour to fit in hotel industry from the early days of their enrollment but when they return from there internship, they show different attitude and behavior. In these regards, an attempt for examining the satisfaction from intern and its effect in change in attitude is made with the aim to examine whether the students intend to change in attitude of undergraduate level students enrolled in Hotel Management.

This research study has the specific objective of examining the significance role of internship programs in changing perception and attitude of Hotel Management students in undergraduate level. Following general objectives are set to attain the general objectives:

i. To explore the satisfaction level of students from internship program.

ii. To examine the attitude changing intention because of internship experience.

iii. To test the relationship between satisfaction level and attitude changing intention in students.

iv. To test the differences in satisfaction level and attitude change intention of students with reference to gender.

\section{Methodological aspect}

This study is based on descriptive research design oriented towards action research. For this purpose, only the undergraduate level hotel management students from five of six different colleges of Tribhuvan University just completed their six months internship are included. Thus, 600 students who just completed their six months long internship 
program as part of the course are considered as population out of which 201 students are taken as sample informants. Convenient sampling and to some extent snow-ball sampling technique are followed to approach the respondents. Among the respondents profile, 58.70 per cent were male while 41.30 per cent were female respondents. Maximum (75.1 per cent) respondents were intern from Malaysia followed by Nepal (14.9) per cent, India (5.5 per cent) and China (4.5 per cent). Likewise, 63.7 per cent respondents were intern from five stars hotels, 23.90 per cent were intern from four stars hotels, followed by three stars hotel ( 9 per cent) and two stars hotel (3.5 per cent).

Well structured questionnaire was prepared to collect the information regarding satisfaction level and intention to change career goals. The questionnaire was administered both in Nepali (national language) and English within the same statement considering the sensitivity of respondent's level of understanding realized from pilot survey.

The study is based on descriptive analysis of the responses. Percentage analysis, mean response, standard deviations, Kendall's tau_b correlation coefficient and independent sample t-test are used to draw the conclusion. Comparative study is conducted to examine the moderating effect of demographic variable i.e. gender of the respondents. SPSS version 23 is used for data recoding and analysis. Reliability test is also used for testing consistency of data. Cronbach's Alpha of the questionnaire including 31 statements measuring satisfaction level from internship was observed to be 0.767. Likewise, Cronbach's Alpha of the questionnaire including 9 Likert items for measuring attitude changing intention was obtained 0.752 which permit the further analysis of data.

\section{Descriptive Analysis}

To measure the satisfaction level of students from internship program, a questionnaire with Five-Point Likert Scale with 31 items was prepared in both English as well as Nepali language. Overall satisfaction level of students from internship program is observed to be 3.55 which indicates that in general, students are satisfied from their internship though the standard deviation accounts comparatively at high level i.e. 1.12 indicating greater variation in response. 
The average response of the students on the statement 'The internship made me face the reality of real work situation' is found to be 4.39 highest among all mean responses on other statements. This means that students feel confident that they can now face job challenges as positive output of internship. This indicates that they had curiosity or doubt about the job challenges which might have not been dealt in class room theory classes.

Likewise, the mean response of the statement 'The memories that the internship made me feel that the hard work was worth it' is observed 4.19 with standard deviation 0.898 . This indicates that, student respondents started to believe that they need to work hard and this made their internship more successful.

Similarly, the average response on the statement 'The internship cultivated my spirit of service for the hotel industry' is observed 3.97 with majority of 72.1 percent satisfied respondents. This indicates the students have gained serving mentality in the industry.

Likewise, respondents have shown positive response in the following statements :

- The internship enabled me to make many friends, expanded my vision, and made me feel that the effort was worth it (Mean 3.98 and s.d. 0.793).

- The results of the internship made me feel that it was worth it to spend time and effort (Mean 3.97 and s.d. 1.131).

- The affirmation of customers from the internship made me feel a strong sense of accomplishment (Mean 4.11 and s.d. 0.769).

- The internship made me feel satisfied because I could apply what I had learnt.

- The internship increased my social networking experiences (Mean 3.35 and s.d. 1.157).

- The internship increased my tolerance and patience for the management of tasks and work (Mean 4.03 and s.d. 0.799).

- The internship helped me improve my personal words and deeds (Mean 3.83 and s.d. 0.982).

- The internship gave me the confidence to change the viewpoints of those who had a negative opinion regarding the hotel industry (Mean 3.9 and s.d. 1.027).

- The internship gave me the desire to think on how to improve the overall quality of the hotel industry (Mean 3.91 and s.d. 0.89). 
- The internship helped me to reflect on my career planning (Mean 3.96 and s.d. $0.894)$.

- The internship inspired me to think that I should continue staying in hotel industry to obtain employment and career (Mean 3.93 and s.d. 1.0795).

- I could not adapt to the life of the internship (Mean 3.93 and s.d. 1.269).

- The internship changed my work values positively (Mean 3.88 and s.d. 1.05).

- The internship made me excited regarding the work environments of the Hotel industry (Mean 3.25 and s.d. 1.34).

Average value of response on the statement 'The internship inspired me to think that I should continue staying in hotel industry to obtain employment and career' is 3.93 with comparatively low standard deviation of 1.095 indicating that, some of the students have changed their mind set to continue their career in the same field. Majority respondents i.e. 70.1 per cent have reported that they satisfy with the statement that they are thinking whether or not they have to continue the career in hotel industry.

Likewise, the weighted mean value of the response on the statement 'The internship made me feel that I was a low-cost labour, which made me feel unpleasant' is 3.64 with majority of respondents i.e. 58.8 per cent which indicates that students have felt that they are low paid labour. They might have higher expectation of cash benefits even from the internship. Career counseling regarding the benefits of internship program before sending them to internship is required to increase their satisfaction.

Similarly, the mean response on the statement 'I felt unpleasant because my position as an intern made it possible to be ordered around by others' is observed 3.48. 57.7 per cent respondents have reported that they are satisfied with the statement. This indicates that students feel that they are the only person to be ordered by their seniors. This explores the issue of underestimating intern employees at the job. Concern authority may facilitate this with dialogue as such feelings of prospect intern students may have detraction towards the industry.

The statement average on the statement 'I felt unpleasant because my position as an intern made it possible to be treated unequally' is obtained 3.67 which is quite high for showing respondents dissatisfaction. Students felt that they are treated unequally because of being intern students. This may be because of lack of orientation regarding the responsibilities, 
and position of the intern students before sending them to intern. The situation might be true. If so, field supervision from college authority should frequently follow the students as well as internship supervisor.

The statement 'The job content of the internship failed to make me learn more.' has the average response 3.79 which is too high showing dissatisfaction towards internship program. Majority of 64.2 per cent respondents agree with this statement which indicates that students are not satisfied towards the job content of internship. This seems that intern students are treated only as an employee rather than students. Hotel management might be interested just to mobilize low cost labour. Hotel must plan the content that needs to be communicated at job. College management must communicate with HR managers and supervisors for designing intern learning plan which facilitates the intern students to learn more systematically and scientifically. In absence of this, internship program could not fulfill the objectives of internship.

The mean value of the statement 'The internship made me disapprove of the payment and fringe benefits of the industry.' is observed 3.67 which indicates majority i.e. 46.3 per cent of respondents are dissatisfied from payment and other facilities provided to them. This could be because of two reasons: students were not properly communicated about payment and fringe benefits or students did not get such facilities as they were informed in advance.

Likewise, the satisfaction level of students on the statement 'The internship made me disapprove of the frequent overtime work of the hotel industry.' is also low as the mean value is higher (3.69). Majority of 46.3 per cent respondents are satisfied with statement. In previous description, students have shown dissatisfaction on the concept of taking them as low paid employees. This could be the reason for involving intern students frequently in overtime duty. Before sending students for intern, college management should have proper counseling about benefit of overtime responsibility. This could be because of lack of feeling of responsibility of intern employees.

Regarding intention for changing attitude of students as a reflection of internship satisfaction, result reveals that respondents are almost neutral (mean 3.34) in responding the statements with large variation in response (s.d 1.3). 
78.1 per cent students have reported that they are willing to make career in the hotel industry while only 9 per cent students are intended to change their career from this industry where overall average of the response is 4.26 indicating the overall satisfaction from internship.

On the statement 'After experiencing the internship, I will recommend other people to engage in the hotel industry' simple majority of the students have shown agreement that they will recommend other people in hotel industry (mean 3.5 and s.d 1.23). 22.4 per cent students have shown their attitude negative towards the statement indicating that they are not satisfied in total while 35.4 per cent respondents are neutral. This could be noticed as serious indicator for the emergency of advancement of the program.

A serious finding of this perceptual survey is that majority 44.8 per cent students are rejecting the statement regarding willingness to join internship for job opportunity. This fact is matching with the satisfaction survey that students are not fully satisfied from their internship. Average mean response (2.78) is also below the average satisfaction level i.e. 3 . This explores the avenue to think planner, as well as college executives to increase the level of satisfaction of students from internship.

Likewise, on the statement 'After experiencing the internship, I am sure that in-college activities are helpful to fulfill the job requirement', respondent's response is negative (mean 2.8, sd 1.02). Majority respondents are either shown neutral response or show disagreement with the statement stating that they are not confident that in-college activities do support for the job demand. College once again should be more aware and dedicated to explore the current job requirement in hotel industry and fulfilling them through in-college activities though the course may not demand.

Similarly, on the statement 'After experiencing the internship, my trust towards college management has been increased', respondents have shown disagreement in majority (46.8 per cent) while 23.8 per cent respondents are neutral with mean response (2.28) indicating the need of serious consideration of college management for facilitating students for internship.

Likewise, respondents have respondents on the following statements with their mean value and standard deviations.

- After experiencing the internship, I am committed to pursue career in hotel industry (mean 4.18, sd 1.32). 
- After experiencing the internship, I have decided college course are appropriately designed as market needs (mean 2.45, s.d 1.51).

- After experiencing the internship, I appreciate the decision for choosing hotel management as my career (mean 4.1, s.d 1.2).

- After experiencing the internship, I felt more dedication is required in hotel industry than in initial expectation (mean 3.77, sd 1.19).

Table 1 : Correlation between Satisfaction Level and intention of changing attitude

\begin{tabular}{|l|l|r|l|}
\hline \multirow{4}{*}{ Kendall's tau_b } & & M_ICA & M_SAT \\
\cline { 2 - 5 } & M_ICA & 1 & $0.210 * *$ \\
\cline { 2 - 5 } & N & 201 & 201 \\
\hline \multirow{2}{*}{$* *$ Correlation is significant at the 0.01 level (2-tailed). }
\end{tabular}

Table 1 shows the correlation between mean value of intern satisfaction (M_SAT) and mean value of intention of changing attitude (M_ICA). Result reveals that there is low but positive and significant relationship between them. This indicates that the level of satisfaction influences in the chances of changing attitude of students.

Table 2 : Descriptive statistics mean differences in level of Satisfaction and intention of changing attitude in reference to Gender

\begin{tabular}{|c|l|r|r|r|r|}
\hline & Gender of Internee & $\mathrm{N}$ & Mean & Std. Deviation & Std. Error Mean \\
\hline \multirow{2}{*}{ M_SAT } & Male & 118 & 3.5085 & 0.4376 & 0.04028 \\
\cline { 2 - 6 } & Female & 83 & 3.4859 & 0.36545 & 0.04011 \\
\hline \multirow{2}{*}{ M_ICA } & Male & 118 & 3.3041 & 0.58748 & 0.05408 \\
\cline { 2 - 6 } & Female & 83 & 2.9598 & 0.4919 & 0.05399 \\
\hline
\end{tabular}

In table 2, there is mean difference of the satisfaction level of male and female. Likewise, the mean difference of the intention of changing attitude of respondents because of intern satisfaction in terms of gender is clearly seen. To conclude whether such differences are significantly large or not, independent sample t-test is carried out as follows : 
Table 3 : t-test statistics of Satisfaction and Intention of changing attitude in reference of Gender

\begin{tabular}{|c|c|c|c|c|c|c|}
\hline & & \multicolumn{2}{|c|}{$\begin{array}{l}\text { Levene's Test } \\
\text { for Equality of } \\
\text { Variances }\end{array}$} & \multicolumn{3}{|c|}{ t-test for Equality of Means } \\
\hline & & $\mathrm{F}$ & Sig. & $\mathrm{t}$ & df & Sig. (2-tailed) \\
\hline \multirow{2}{*}{ M_SAT } & Equal variances assumed & 2.628 & 0.107 & 0.384 & 199 & 0.701 \\
\hline & Equal variances not assumed & & & 0.396 & 193.13 & 0.692 \\
\hline \multirow{2}{*}{ M_ICA } & Equal variances assumed & 0.8 & 0.372 & 4.369 & 199 & 0 \\
\hline & Equal variances not assumed & & & 4.505 & 192.95 & 0 \\
\hline
\end{tabular}

For instance, F-Values of Lavene's test for equality of variance for mean of satisfaction level is insignificant with $\mathrm{p}$-value greater than 0.05 . This gives the evidence of equal variance of respondents. This tells that the variance for male and female are not significantly different. So, to decide whether the mean difference is significantly large or not, we have to follow the first line i.e. there is 'equal variance' assumption. P-value with that assumption is greater than 0.05 indicating that the difference is insignificant. Thus the hypothesis of 'sample means are same' could be accepted. This provides sufficient evidence to accept the null hypothesis i.e. the satisfaction level of male students and female students is same.

Likewise, F-Values of Lavene's test for equality of variance for mean of behavioural intention level is insignificant with $\mathrm{p}$-value greater than 0.05 . This indicates that the variance of behavioural intention of male and female respondents is same i.e. not significantly different. So, to decide whether the mean difference is significantly large or not, assumption of 'equal variance' is accepted. P-value with that assumption is less than 0.05 which provides the sufficient evidence to reject the hypothesis i.e. the intention of changing attitude of male students and female students is different. From the table, the mean value of intention of male is higher than that of female respondents. This indicates that the chance for changing attitude by male students is high. 


\section{Conclusion}

Satisfaction is the resultant of various factors though the overall satisfaction seems to be above par. This means hotel management students are satisfied in general, from the internship program. Students have still strongly convinced and attached with their career choice decision. Attitudes, knowledge, confidence, and competency are thought to closely associated (Bedregal, O'Connell, \& Davidson, 2006; Siegfried et al., 2007). Chen et al., (2011); Richardson, (2008), Feldman \& Weitz, (1990) have explored the alarming fact that internship experience too often students want to stay in the same career area, supporting the findings of the study. As Bould et al. (in Richardson, 2008) has warned the concerned authority that the experience may actually lead to the students not pursuing a career in the industry at all. Irrespective of this fact, students from Hotel Management students, though they have average satisfaction level, majority of them want to continue the same career area. But, they have complaints on college management as well as incollege activities.

Decision maker should analyze such factor affecting the satisfaction from internship. College management need to orient the students regarding the internship program, working environment, expected behaviour, and outcomes. They should be prepared for the industry-requirements with more strong and dedicated in-college activities to recover the college prestige and students huge investment.

\section{REFERENCES}

Bedregal, L. E., O'Connell, M., \& Davidson, L. (2006). The recovery knowledge inventory: assessment of mental health staff knowledge and attitudes about recovery. Psychiatric Rehabilitation Journal, 30(2), 96-103.

Calloway, D., \& Beckstead, S. M. (1995). Reconceptualizing internships in management education. Journal on Management Education, 19, 326-341.

Chen, C. T., Hu, C.C., \& Chen, C.F (2011). A study of the effects of internship experiences on the behaviour intentions of college students majoring in leisure management in Taiwan. Journal of Hospitality, Leisure, Sport and Tourism Education, 10 (2), 61-73.

Crowe, T.P., Kelly, P., Pepper, J., McLennan, R. \& Deane, F.P. (2013). Service Based Internship Training to Prepare Workers to Support the Recovery of People with Co- occurring Substance Abuse and Mental Health Disorders. International Journal of Mental Health and Addiction, 11 (2), 269-280. 
Dortch, D. (2003). A complete guide to internships. Washington Post. Retrieved June, 2015, http://www.washingtonpost.com/wp-dyn/articles/A16305-2003 Mar12. html.

Haung, I. C. \& Haung, P. W. (2004). The relation between practical training values and job involvement: A study of college students majoring in tourism, leisure, recreation, and hospitality. Journal of Tourism Studies, 10(1), 63-79.

Hurst, J.L., Good, L.G. \& Gardner, P. (2012). Conversion intentions of interns: what are the motivating factors?. Education + Training, 54(6), 504-522.

Knechel, W. R., and Snowball, D. (1987). Accounting Internships and Subsequent Academic Performance: An Empirical Study. The Accounting Review, October, 799- 807.

Rok, M. (2013). Undergraduates' Experience and Perceptions of Tourism and Hospitality Work Environments. Academic Journal of Interdisciplinary Studies, Published by MCSER-CEMAS-Sapienza University of Rome, 2 (2), 61-70. Doi:10.5901/ajis.2013.v2n2p61.

Siegfried, N., Ferguson, J., Cleary, M., Walter, G., \& Rey, J. M. (2007). Experience, knowledge and attitudes of mental health staff regarding patients' problematic drug and alcohol use. Australian and New Zealand Journal of Psychiatry, 33(2), 267-273.

Wang, Y. F. (2002). Evolution of higher education in hospitality in Taiwan. Journal of Human Ecology and Technology, 3(4), 453-464.

Watson, H. E., Maclaren, W., Shaw, F., \& A, N. (2003). Measuring staff attitudes to people with drug problems: the development of a tool. Edinburgh: Effective Interventions Unit, Scottish Executive Drug Misuse Research Programme.

West, A. J. \& Jameson, S. M. (1990). Supervised work experience in graduate employment. International Journal of Contemporary Hospitality Management, 2(2), 29-32. 